\title{
Looking for Moral Responsibility in Ownership: A Way to Deal with Hazards of GMOs
}

\author{
Zoë Robaey
}

Accepted: 5 September 2014/Published online: 17 September 2014

(C) The Author(s) 2014. This article is published with open access at Springerlink.com

\begin{abstract}
Until now, the debates around genetically modified seeds in agriculture have converged towards two main issues. The first is about hazards that this new technology brings about, and the second is about the ownership of seeds and the distribution of their economic benefits. In this paper, I explore an underdeveloped topic by linking these two issues: how ownership shapes the distribution of moral responsibility for the potential hazards of genetically modified seeds. Indeed, while ownership is debated in terms of economic rights and hazards in terms of "good" or "bad" science, no one has looked at whether or not we could and should ascribe and distribute moral responsibility for hazards based on ownership of genetically modified seeds. I argue that we should. Using the notion of ownership as a bundle of rights, I argue that from a moral perspective, the genetically modified seed has several owners at the same time. Although different owners may not have the same economic rights over the seed, they all have a moral responsibility, possibly to varying degrees, for the potential hazards brought about by the seed. Secondly, I argue that, as long as a seed carries the character trait that was intentionally modified, then it calls for moral responsibility. All in all, I formulate a way for linking issues of ownership and hazards of genetically modified seeds in agriculture through the concept of moral responsibility.
\end{abstract}

Keywords Ownership · Moral responsibility · Hazard · Risk · Uncertainty · Genetically modified seeds 


\section{A Constructive Proposal}

The discussion about genetically modified organisms (GMOs) has been revolving around issues of risks and issues of ownership. The only way these two issues have been linked in law and policy are through the concept of liability for damages, i.e. people planting GMOs can be held liable for damages to organic farmers harvest in the European Union (EU) (c.f. Koch 2007) or internationally for any "possible damage caused by the imported GMOs" by the exporting party (Kuala LumpurNagoya Supplementary Protocol 2011). In the case of the EU, the notion of damages is very specific; it applies to organic produce that would lose their certification in cases of contamination with GMOs. In the case of the Nagoya Protocol, the term possible damage is much more encompassing, but also loosing specifity by speaking of "adversely affect the conservation and sustainable use of biological diversity, taking also into account risks to human health." (ibid.). The underlying idea, in plain English, is that if one brings in something that has potential risks for other things, one must take measures to prevent those risks, or else one will be held liable for damages caused by one's property. While there may be a range of legal provisions for this in different countries, most of these provisions, as shown with the examples above, apply to liability. Liability is, however, only one application of moral responsibility, which is a backward-looking one (van de Poel 2011), i.e. an owner can be held responsible if the thing she owns has already caused harm. In this paper, I aim to expand the horizon of the link between moral responsibility, risk and ownership by exploring why and how ownership calls for forward-looking moral responsibility, i.e. a proactive moral responsibility for harms that have not yet happened.

Van de Poel and Nihlén Fahlquist (2013) argue that the relation between risk and moral responsibility has been surprisingly understudied. An interesting observation they make with regards to forward-looking moral responsibility is that it is often linked to decisions and control, i.e. in the case of GMOs, the decisions of several actors to produce and use genetically modified seeds. Moreover, Nihlén Fahlquist (2006) argues that there are two values at stake in ascribing moral responsibility: effectiveness and fairness, which are respectively associated with consequentialist and non-consequentialist understandings of moral responsibility. She also argues that we need not choose one value over the other, but that ascribing moral responsibility is about striking a balance between these values.

In order to establish the link between ownership and moral responsibility for hazards of genetically modified seeds in agriculture, one sees that there is a decision involved, and that from the perspective of fairness, moral responsibility should be assigned to those who take these decisions. In other words, it is reasonable to expect an owner who will have benefits from its property to also have duties and responsibilities. For instance, a company developing and selling genetically modified seeds, and a farmer planting and harvesting them, all do so because they expect benefits from the seed. It is, therefore, reasonable to expect that these actors be given special duties or responsibilities in regards to their activities (or decisions). It is important to note that these observations could very well apply to other ways of creating new varieties of seeds, however, GMOs being considered novel organisms, 
in most countries, call for special measures, whereas conventionally bred seeds do not. I will not address the legitimacy of such differentiation here. What is important to observe, is that according to legislation in several countries, this novelty raises suspicions of risks. While the literature mostly speaks of risks, this paper seeks to extend the link between moral responsibility and risk to moral responsibility and uncertainties as well as ignorance. Uncertainties are known events with unknown probabilities, and ignorance describes things that simply cannot be predicted (c.f. Felt et al. 2007). In this paper, I focus on the value of fairness, i.e. why it is justified to ascribe owners of genetically modified seeds forward-looking moral responsibility. This is especially relevant in the case of genetically modified seeds where (1) there are several owners of the seed at the same time and (2) there are many uncertainties and ignorance linked to the use of genetically modified seeds. In this paper, I will show why this approach allows connecting debates, and defining a framework of shared moral responsibility that allows dealing with hazards of genetically modified seeds.

\section{GMOs, Hazards and Ownership}

There is not one, but several debates around GMOs, which, however, seem to converge towards two main issues: hazards and ownership. Both issues are also dependent on existing regulatory and legal institutions that do not seem to be able to keep up with the challenges GMOs bring. Also, I choose to speak of hazards, which include risks, uncertainties and ignorance.

\section{GMOs and Hazards}

Let us begin with hazards. GMOs, also nicknamed 'Frankenfoods' by certain critics (c.f. van den Belt 2009 for a detailed overview of ethical issues in biotechnology), raise worries for environmental and human health as new organisms that are consumed by humans (or animals for eventual human consumption) and are planted alongside conventionally bred crops. To deal with these risks, different countries or regions have created ways to deal with them. Høyer Toft (2012) points out that, at the international level, governance of GMOs has two purposes: to set guidelines for safety and risk, and to facilitate free trade (p. 227). He outlines the guidelines that deal primarily with safety and risk, which are: (1) the Cartagena Protocol on Biosafety under the Convention on Biological Diversity, (2) the International Treaty on Plant Genetic Resources for Food and Agriculture by the Food and Agriculture Organization, (3) EU directives on deliberate release, labelling and traceability and (4) several national legislations. However, the ones that have as primary goal to facilitate free trade also contain measures regarding safety and risk. These are: (1) the World Trade Organization's (WTO) (a) Technical Barrier to Trade Agreement (TBT), (b) Sanitary and Phytosanitary Agreement (SPS) (c) the Agreement on Trade-Related Aspects of Intellectual Property Rights (TRIPS) and (d) Article XX of the General Agreement on Tariffs and Trade (GATT), and (2) The Food and Agriculture Organization's Codex Alimentarius. While Høyer Toft (2012) comes to 
the conclusion that these institutions allow for global justice claims to be made, he recognizes that they are attached to issues of risks and safety that are themselves more complicated. Indeed issues of hazards in GMOs remain very contested. In the EU, a de facto moratorium on GMOs was put in place between 1999 and 2004, while the EU was trying to agree on Directives to regulate them. No new GMO was approved during that period, which led to WTO disputes DS 291, 292, 293 initiated by the US, Canada and Argentina (WTO 2010). Through an historical analysis, Lynch and Vogel (2001) remark that

While the EU has struggled to put into place a regulatory structure capable of adequately protecting the safety of food produced in fifteen Member States, each with their own regulatory institutions, and each Member State is attempting to upgrade its own regulatory institutions, the United States has in place a relatively well-established set of national regulatory bodies which appear to function reasonably well. In a sense, while the American regulatory structure underwent its baptism of fire, Europe's is only beginning to address the challenge of balancing scientific risk assessment with public confidence.

One could think that it is then just a matter of time until all regulatory bodies are up to speed and GMOs are safely regulated. However, the debates in the EU have raised serious questions on how to deal with the lack of full scientific knowledge. In addition, there are fervent opposing voices to GMOs, such as those from the ETC Group or the Third World Network. It is a struggle for policy makers to have to make decisions without having full information. Trying to elucidate this science/policy debate, Hansson (2008) distinguishes between theoretical and practical rationalities, i.e. what to believe and what to do, respectively. According to Hansson, the question of what to do is one that pertains to risk management for policy makers and "the task of scientists [is] to explain what science can and cannot do" (2008, p. 147). While this distinction is helpful to understand the limits of roles, Hansson also recognizes that this is not the case in reality. Indeed, Van Asselt and Vos coin this as the uncertainty paradox, "an umbrella term for situations in which uncertainty is present and acknowledged, but the role of science is framed as one of providing certainty" (2010, p. 282). Also, from a regulatory perspective, Levidow and Carr write, "These products have been put on trial also in the scientific-managerial sense, as regards what risks must be tested and managed, as well as what responsibilities should be assigned to agro-industrial operators." (2007, p. 409). There is still a lot to be debated with regards to the best way to deal with hazards. While Levidow and Carr describe the responsibility being shifted from the regulator to the agro-industry, Van Asselt and Vos describe the current way of dealing with uncertainty as one of organized irresponsibility. It seems that, even doing the best we can to responsibly tackle hazards of GMOs, there are limits to what we can do that are simply linked to limits in our knowledge. While institutions are set up to deal with risks, uncertainties and ignorance both remain unaddressed. This is where moral responsibility becomes important. Before going into more details on the role of moral responsibility, and in order to provide a constructive account of moral responsibility, I need to introduce the other pole of disagreeing opinions around GMOs that also lies within institutions-this time not regulatory ones, but legal ones. 


\section{GMOs and Ownership}

The other problem with GMOs, discussed in the literature, is one of ownership, or property. A 2011 study by the ETC group on 'Who will control the Green Economy' reports that, "just three companies control more than half of the global commercial market for seed" (ETC 2011, p. 22). The concentration of ownership for genetically modified seeds has become more and more evident through a series of legal battles that have made the headlines since the late 1990s. These legal battles highlight the constant challenges that the current ownership system for genetically modified seeds is facing.

The first case to take prominence is the one of Percy Schmeiser, a Canadian farmer, who discovered that his field had been contaminated by RoundUp Ready Canola. He was found guilty of having seeds that he had not legally purchased (Monsanto Canada Inc v. Schmeiser 2001). Although this story does not end here, similar events have occurred elsewhere. For instance, farmers in Argentina have not been paying royalties to Monsanto after purchasing the first batch of RoundUp Ready Soybean, finding ways within national intellectual property laws to challenge Monsanto (Filomeno 2013), and now Monsanto is releasing a new version of its modified soy and putting a lot of efforts in writing up contracts that will uphold their economic rights. Recently, a US farmer, Hugh Bowman, lost a lawsuit against Monsanto in which he was defending the right of farmers to save seeds, including genetically modified seeds. The US Supreme Court upheld Monsanto's rights over the seeds as their property (Bowman v. Monsanto Co. et al. 2013).

In those cases, the problem is not that people are opposed to GMOs. To the contrary, they highlight how the institutions of property are changing agricultural practices. Seed saving, a very old practice, becomes illegal; contracts regulate which seeds may be harvested by whom and when. In the literature, these institutions are challenged but also often linked to the issue of bio-piracy, i.e. companies stealing traditional knowledge for applications in biotechnology. Challenging ownership structures is often seen in the context of opposing the use of biotechnology in agriculture. Risks, uncertainties and ignorance are then invoked. An interesting case that already links the issue of ownership to the issue of hazards is the pre-emptive lawsuit of Organic growers v. Monsanto. In this lawsuit, a coalition of 80 farmers sued Monsanto so that, in the event of contamination of their fields with GM crops, they would not be held responsible. The vocabulary in the lawsuit is very adamant that GMOs are bad and that these growers want to protect themselves, both from planting seeds they think are bad, and from having to pay royalties for using seeds they never wished to have in their fields (OSGATA 2011). This case suggests that those who choose to own, plant and harvest GM seeds expose others to hazards. Since GM seeds are perceived as bad by some, and good by others, and as we saw earlier, regulation does not seem to solve this issue, we can infer that there is a gap in dealing with hazards of GM seeds. Exploring the link between ownership and moral responsibility might provide for some answers concerning this gap. Indeed, instead of contesting ownership structures altogether, one may provide a more constructive account of how ownership could help dealing with hazards from GMOs. 


\section{As, Thompson writes}

In fact, owning property rights in such technologies may be instrumental to controlling and limiting their use. There may thus be legal grounds for recognizing a property right even when there are also compelling arguments to restrict a technology's use. Arguing that a technology is risky, harmful or downright evil is thus not in itself an argument against patents or other forms of intellectual property rights material to the technology. Nor is it clear that food and agricultural biotechnology would be stopped or even substantially slowed by an absence of such rights. (2007, p. 254)

There is a link between the issues of ownership and hazards, but as Thompson writes, the presence or absence of property rights will not as such change the use and spread of GMOs, and will not change the lack of means to deal with uncertainties that might arise from GMOs. Also, GMOs in agriculture are a technology that has been around for the past 20 years and their use is only increasing; the problem of how to deal with their uncertainties remains. So far, a constructive discussion on how to deal with this problem from the perspective of moral responsibility is lacking. It is in this context that I formulate my proposal to link hazards and ownership through the notion of moral responsibility. While I will go in much more detail in the coming sections, I aim to refine the following formulation, which is the thesis I defend in this paper: The owner of a genetically modified seed has moral responsibility for the hazards the seed might create.

\section{Ownership and Moral Responsibility}

\section{Conceptions of Ownership and the Bundles of Rights}

I suggest that one can have moral responsibility for hazards potentially caused by a genetically modified seed that one owns. Before further expanding on this, it is important to position this argument within existing theories of ownership. The notion of ownership has existed for a very long time, and is linked to problems of justice, fairness, exploitation, etc. (for a brief yet comprehensive overview of property and ownership in philosophy, see Waldron 2012). In respect to biotechnologies, Thompson (2007) summarizes these conceptions into two approaches: an instrumental one and an ontological one. In the instrumental one, property is a construct that allows the realization of ethical goals, and the ontological one questions whether or not something can be owned. While both of these approaches are relevant to discussing the link between ownership and moral responsibility, this paper focuses on the instrumental approaches of ownership because genetically seeds are currently owned. The instrumental approach is well known, for instance, with the use of patents to encourage innovation and create social value. The argument at hand takes a broader approach using the notion of "bundle of rights", which include patents that are essentially a certain type of rights over an idea and its derivatives. 
When writing about bodily property, (Bjorkman and Hansson 2006) use the notion of the bundle of rights. They offer an extensive review of different bundles of rights in the literature to find Tony Honoré's to be the most comprehensive one. Honoré (1961) endorses a liberal notion of individual ownership, where ownership allows the "greatest interest in a thing". According to him, standard incidents of ownership include the rights to possess, to use, to manage, to income, to the capital, to security, as well as the incidents of transmissibility, absence of terms, the prohibition of harmful use, the liability to execution and its residuary character. All of these incidents provide insight into what ownership actually means. I would like to point out that, what Honoré calls the prohibition of harmful use, Björkman and Hansson call the duty to prevent harm. I will continue using that phrasing throughout the remainder of this paper, as it makes for a semantic counter balance to the terminology of rights. While Honoré does not phrase it as such, it is clear that he means it as a duty when he writes on the prohibition of harmful use, "These and similar limitations on the use of things are so familiar and so obviously essential to the existence of an orderly community that they are not often thought of as incidents of ownership; yet, without them 'ownership' would be a destructive force" (1961, p. 123) .The two most interesting elements of Honoré's arguments on ownership for the purpose of this paper are (1) the prohibition of harmful use, which puts boundary conditions on many of the rights mentioned above, and (2) what Honoré calls 'split ownership', on which I will expand in the coming paragraphs.

\section{Split Ownership and Shared Responsibility}

Honoré speaks of split ownership, and also suggests that several people can be owners of the same thing at the same time, but with different bundles of rights. This observation is pivotal when thinking of the moral dimension of ownership for genetically modified seeds. It raises questions such as: if owners have different bundles of rights, do they all have a duty to prevent harm? Do varying degrees of economic rights mean varying degree of the duty to prevent harm? What does the duty to prevent harm mean practically? I will not answer all these questions here. Rather, I will focus on articulating part of the last one, i.e. the relationship between ownership and moral responsibility. It seems that there is a shared moral responsibility through the duty to prevent harm because there are several owners of a genetically modified seed at the same time.

Through the journey of the GM seed, from the scientist who invents it, to the farmer who sows it and reaps the harvest, to the company who markets the harvest, or even the retailer that sells its products; different actors are involved. All these actors may be conceived of as owners with different bundles of economic rights. This is not a new idea in itself. Indeed, Honoré already speaks of it as split ownership, and it echoes other scholarly work on property, such as the one of Schlager and Ostrom (1992). In that paper, the authors differentiate between an owner, a proprietor, a claimant and a user. Basically, all these different labels represent different bundles of economic rights over a good, i.e. they could also all be called owners with differing bundles of economic rights found in Honoré's list. Adopting such a broad definition of the word owner allows thinking more broadly of how moral responsibility is 
shared between owners. While economic rights can easily be bundled into different types of ownership, Honoré's duty to prevent harm remains left aside in other taxonomies such as the one presented in Ostrom and Schlager.

\section{The Duty to Prevent Harm or the Responsibility to Do No Harm?}

Let us now turn to the duty to prevent harm. Interestingly, if we put the ownership of a thing in its context, the duty to prevent harm might pose boundary conditions on economic rights. For instance, the duty to prevent harm might limit how the right to manage is implemented in agriculture, i.e. which pesticides are to be used, etc. Secondly, the duty to prevent harm presents a duty to the owner directly. Indeed, as discussed in the previous section, GMOs, when considered as novel organisms, raise fears of risks that require different owners (societal actors) to follow a number of guidelines on how to use these most safely, according to different legislations.

Then, what is the difference between a duty to prevent harm and a responsibility to prevent hazards? Goodin (1986, p. 50) argues that, "responsibilities are to consequentialist ethics what duties are to deontological ones". While both responsibilities and duties are prescriptions, these notions have different implications. For Goodin, while both responsibilities and duties aim at a certain state of affairs, the crucial difference is that a duty will have a reference to a specific agent and a specific action, or restriction of a specific action, whereas responsibilities will not "specify any particular actions which [an agent] must perform or refrain from performing" (p. 51). In other words, duties involve an agent that has to do a specific action, which implies that this duty hinges upon the realisation of those specific actions that, in turn, should result in the realisation of a certain state of affairs.

The problem with this notion is exactly this specificity. Under many regulatory systems, GMOs undergo extensive risk assessment and a certain number of actions are thereby defined. This becomes apparent when reading national legislation on GMOs, for instance in the UK, the Genetically Modified Food (England) Regulations of (2004), the emphasis on compliance requirements makes up an important part of the law, so speaking of duties, which agent has to do or not do certain things according to the law. Yet, responsibilities in the sense described by Goodin are absent. So, one can fulfill duties as described by the law but it might not lead to a desired state of affairs, and no one would be responsible if the agents involved fulfilled their duties and the desired state of affairs would not be met. This is exactly the moral conundrum that GMOs pose. While their risks can be researched, known and managed, the uncertainties and ignorance attached to their use cannot be predicted until they reveal themselves. In the case where we would only speak of duties, no agent bears the active forward moral responsibilities of achieving a desired state of affairs, so there is no range of action possible under duties besides the ones that are defined.

This is why the notion of responsibility to prevent harm becomes necessary to use when speaking of uncertainties and ignorance linked to a technology. Goodin himself writes that responsibilities "count as genuine responsibility rather than a duty, provided that injunction is understood merely to set [an agent] a goal and leave open the choice of actions to be taken pursuant to that goal" (p. 51). Goodin 
describes responsibilities as self-supervisory whereas duties "demand specific performance" (p. 52). Here, it is important to pause and expand on what "selfsupervisory" implies if both duties and responsibilities relate to a moral agent who ought to see to it that a certain state of affairs applies. For Goodin, self-supervisory means that (1) a moral agent ought to monitor that a state of affairs is realised, and (2) a moral agent has discretionary powers. These two aspects combined give a moral agent the ability to improvise, or react to uncertainties as they reveal themselves. Responsibilities allow a choice of action in Goodin's own words. Using the notion of responsibility instead of duty thereby fills the lacuna in dealing with uncertainties and ignorance because it is not limiting and because it relies on judgement of the agent to choose how to act towards a certain desired state of affairs. Indeed, to simply speak of a duty to prevent any harm would limit action to dealing with known risks, and potential harm from GMOs can thus be prevented with adequate risk management. However, uncertainties and ignorance make it impossible for this duty to be fulfilled. It seems, therefore, that using a consequentialist notion of responsibility is better suited to the case of GMOs than the notion of duty. Indeed, preventing harm is far from qualifying as a specific performance, especially under uncertainty. Therefore, the duty to prevent harm needs to be reformulated into a responsibility. Since responsibilities focus on outcomes and are self-supervisory-i.e. involve monitoring to see to it that a certain state of affairs is realised, and giving discretionary powers to the moral agent-a possible translation of the duty to prevent harm is a moral responsibility for nonmalevolence. So, in a way, translating the duty to prevent harm to a moral responsibility for non-malevolence might promise the best possible outcome. Here, the emphasis is on the word possible because of the self-supervisory nature of responsibility that allows a moral agent to explore all possible courses of action to be non-malevolent. For simplicity, I call this the responsibility to do no harm.

This responsibility to do no harm implies that a moral agent can act according to her own judgement, but it also does not exclude following laws. Without going into too much detail, it is easy to imagine how judgement may be formed through education, experience, etc. For instance, a farmer planting genetically modified seeds would have the responsibility to monitor, or to have someone monitor, certain important things for a particular goal, such as producing good crops. Upon unexpected observations, the farmer would then have the possibility to react, adjust, or even perhaps stop certain things. This opens a range of other questions that cannot be addressed in this paper but should be addressed, like how does a moral agent know what to monitor and where does this responsibility stop? However, the important point made here, is that a responsibility to do no harm is better suited to dealing with hazards than a duty to prevent harm, because it gives the moral agent more room for action.

So, to follow up on the previous sections, we can now state that: The owner of a genetically modified seed has moral responsibility to do no harm with that seed and there can be several owners of the said seed at the same time that will share moral responsibility. 


\section{When Does Moral Responsibility for Owners of Genetically Modified Seeds End?}

\section{Using the Type/Token Distinction}

Now that we have an idea of what the moral dimension of ownership of genetically modified seeds means, it might be useful to reflect on what the moral dimension of ownership can be applied to. Indeed, the genetically modified seed is more than a seed. It contains the modified gene sequence, which is patented, and it will produce new, identical seeds that will most likely contain the modified traits. When we follow the journey of a GM seed, it becomes clear that the seed is an intentional artefact, that also happens to be a living artefact, and constitutes an innovation. For the purpose of clarity, I would like to apply the so-called type/token distinction to the genetically modified seed and all further deriving seeds. Coming from the philosophy of language, this distinction allows making a difference between the idea of a thing (the type), and the expression of that idea (the tokens). Indeed, the idea of a particular drought-resistant maize, how to create it, or even the gene sequence coding for this trait, is the type. The type, then, is what is patented and the seeds are tokens for which different bundles of economic rights are allocated. Patents are allocated differently in different countries, but they all represent a restriction on use and reproduction of the idea, with varying conditions. Koepsell (2009) argues that,

We often own things in only limited ways. Some people lease cars and even though they might hold the title, their use of the car is restricted in a number of ways. The same is true for mortgaged properties. The books in their personal libraries are fully theirs, as are the DVDs and CDs they own, but their rights over those are also limited. They may not copy or otherwise reproduce them, and they may not perform or display them for profit without permission of the author. They own the tokens but not the types. The same is true for one fifth of our genes. We own the tokens but not the types. Yet there are clear differences between works of authorship and the complex polypeptide chains that exist in each of us and nearly every cell of our bodies. (p. 156)

Here, Koepsell points to two things. First, "owning things in limited ways" refers to having a different bundle of economic rights over that thing. Second, he points to the case where people have limited ownership of their own genes. This was written before the US Supreme Court decision on patenting human genes but Koepsell already makes the argument that the Supreme Court will later follow in regard to the moral inadequacy of such a practice. Indeed, patenting human genes restricted access of certain genes to medical research, or for the case of the lawsuit, certain screening tests for breast cancer. Altogether, this underlines that legal and institutional arrangements are also not always in line with morality. This might indicate why the lawsuits described at the beginning of this paper pointed at problematic situations with the use of genetically modified seeds in agriculture. 
Placing the Locus of Responsibility in the Seed

Both the ownership of the type (patent) and the token (seed) have a moral dimension. However, most risks, uncertainties and ignorance, natural and social, arise through the use of the token and not the type. Of course, ownership of the type does have a moral dimension in the sense that owners of a patent that could be harmful have the duty to prevent harm, for instance. New patented inventions often need to undergo a risk assessment before they can be put onto the market, i.e. turned into types, following the regulations set out for the product in question. An example of this is the international agreement regarding nuclear proliferation, in which there is strict control of anyone who has access to the idea and means to build a nuclear bomb. This moral dimension of ownership becomes particularly important with tokens in the case of genetically modified seeds, because they are seeds.

Indeed, in the case of the genetically modified seed, the complexity of the token comes in that it carries that patented information from generations to generations by itself. A plant growing from a seed will produce new identical seeds. This selfreplicating character, together with the ease with which seeds can spread, e.g. a gust of wind, an animal passing by, etc., both make for a difficult control over the tokens. Self-replication and dispersion of seeds pose a great challenge to monitoring and controlling the invention, which are primordial elements in preventing possible harm caused by a technology. I place the locus of the moral dimension of ownership in the token, and not of the type, because of the complexity of seeds. Nevertheless, while I place the locus of moral responsibility on the token, ownership begins with the type. Therefore, the modification also justifies owning the seed. This might be different for other technologies with different characteristics.

Tokens are, however, also not simply tokens. Usually, tokens are expression of a type, but, in the case of seeds, tokens become expressions of themselves. Let's call the first seeds produced as a result of the type the parent token, and all seeds coming from the parent tokens, children tokens. Children tokens, in turn, can bear more children tokens, and so on and so forth. I suggest that a genetically modified seed is no longer a token of a type, when it has lost the character trait that was intentionally brought about by the type as invention in the first place. Another argument supporting this statement is that the genetically modified seed is considered potentially dangerous because of the introduced trait.

It is important to follow the seed through generations for the moral dimension of ownership. Indeed, if the invention of a seed turns out to be harmful, the harm would not stop at the parent token. Ideally, the seed industry would like their seeds to be bought anew each year, and have the old one destroyed. Unfortunately for them, this is not the case. Many seeds are saved, intentionally, or unintentionally, legally or illegally. Many seeds disperse and contaminate other fields. And so the parent tokens will almost always have children tokens, and the children token as well in turn, etc.

Hence my suggestion of the following formulation: The owner of a genetically modified seed has moral responsibility to do no harm with that seed and there can be several owners of the said seed at the same time that will share moral responsibility for each seed that has the modified character trait and is currently owned. 


\section{Conclusion}

In this paper, I set the stage for ascribing a moral responsibility to do no harm on the basis of ownership, in the case of genetically modified seeds in agriculture. Not only does my framework allow for a constructive discussion on the use of GMOs, but it also empowers and responsibilizes actors, or moral agents, who choose to use genetically modified seeds.

I argue that on the basis of fairness, owners should have moral responsibility because they decide to use GMOs and also because they will reap benefits from their use. Moreover, based on the bundle of rights, I use Honoré's claim of split ownership, i.e. that there can be several owners at the same time, to argue that responsibility is shared. Indeed, owners have a duty to prevent harm, which I translate in a responsibility to do no harm using Goodin's distinction of duty and responsibility. This translation gives room for owners to act responsibly and react to uncertainties as they reveal themselves, as opposed to a duty that is too specific and does not allow for improvisation. Last but not least, this responsibility extends for as long as the intentionally modified trait is to be found in the seeds. This is the case because the ownership of the seed depends on this modification and because it is the modification that raises suspicions of potential hazards.

Speaking of responsibility ascription in a forward-looking way allows for a more pro-active and constructive account of problems that have been impeding an ethically desirable use of genetically modified seeds. Nevertheless, many open questions remain: Do the differing bundles of rights have an impact on the extent of the moral responsibility of the owner? Indeed, do more economic rights increase one's moral responsibility to do no harm? Or are these independent and, as soon as one comes in some form of ownership, then full moral responsibility comes with it? Also, what does this responsibility entail? If owners have the responsibility not to do harm, then they must monitor and react. What exactly should be monitored, and by whom? Last, but not least, this paper focussed on the instrumental definition of ownership, but what do ontological considerations of ownership change with respect to the ascription of moral responsibility? Further work on these questions will continue my attempt at arguing that linking ownership and moral responsibility constitutes a positive way to deal with the hazards of genetically modified seeds. Maybe there is hope for the long-polarized GMO debate to become a constructive discussion on how our societies ought to act responsibly in securing the future of our food systems.

Acknowledgments This paper was written as part of the research program 'New Technologies as Social Experiments', which is supported by the Netherlands Organization for Scientific Research (NWO) under grant number 016.114.625.

Open Access This article is distributed under the terms of the Creative Commons Attribution License which permits any use, distribution, and reproduction in any medium, provided the original author(s) and the source are credited. 


\section{References}

Bjorkman, B., \& Hansson, S. O. (2006). Bodily rights and property rights. Journal of Medical Ethics, 32(4), 209-214.

Bowman v. Monsanto Co. et al. (2013). Supreme Court of the United States. http://www.supremecourt. gov/opinions/12pdf/11-796_c07d.pdf. Accessed 18 March 2014.

ETC Group. (2011). Who Will Control the Green Economy? http://www.etcgroup.org/sites/www. etcgroup.org/files/publication/pdf_file/ETC_wwctge_4web_Dec2011.pdf. Accessed 18 March 2014.

Felt, U., Wynne, B., Callon, M., Gonçalves, M. E., Jasanoff, S., Jepsen, M., \& Joly, P. et al. (2007). Taking European Knowledge Society Seriously. Report of the Expert Group on Science and Governance to the Science, Economy and Society Directorate, Directorate-General for Research, European Commission. Brussels: Directorate-General for Research, Science, Economy and Society.

Filomeno, F. A. (2013). How Argentine farmers overpowered Monsanto: The mobilization of knowledgeusers and intellectual property regimes. Journal of Politics in Latin America, 32(3), 35-71.

Goodin, R. E. (1986). Responsibilities. The Philosophical Quarterly, 36(142), 50-56.

Hansson, S. O. (2008). Regulating BFRs_-from science to policy. Chemosphere, 73(2), 144-147.

Honoré, T. (1961). Ownership. In A. G. Guest (Ed.), Oxford essays in jurisprudence: A collaborative work. Oxford: Oxford University Press.

Høyer Toft, K. (2012). GMOs and global justice: Applying global justice theory to the case of genetically modified crops and food. Journal of Agricultural and Environmental Ethics, 25(2), 223-237.

Koch, B. A. (2007). Liability and Compensation Schemes for Damage Resulting from the Presence of Genetically Modified Organisms in Non-GM Crops. Research Unit for European Tort Law of the Austrian Academy of Sciences in cooperation with ECTIL (European Centre of Tort and Insurance Law). http://ec.europa.eu/agriculture/analysis/external/liability_gmo/. Accessed 6 March 2014.

Koepsell, D. R. (2009). Who Owns You?: The Corporate Gold-Rush to Patent Your Genes. Chichester, West Sussex, U.K.; Malden, MA: Wiley-Blackwell.

Levidow, L., \& Carr, S. (2007). GM crops on trial: Technological development as a real-world experiment. Futures, 39(4), 408-431.

Lynch, D., \& Vogel, D. (2001). The Regulation of GMOs in Europe and the United States: A Case-Study of Contemporary European Regulatory Politics. Council on Foreign Relations. http://www.cfr.org/ agricultural-policy/regulation-gmos-europe-united-states-case-study-contemporary-europeanregulatory-politics/p8688. Accessed 23 Dec 2013.

Monsanto Canada Inc. v. Schmeiser. (2001). Federal Court of Canada. http://decisions.fct-cf.gc.ca/site/fccf/decisions/en/item/38991/index.do. Accessed 15 Jan 2014.

Nihlén Fahlquist, J. (2006). Responsibility ascriptions and public health problems. Journal of Public Health, 14(1), 15-19.

OSGATA. (2011). OSGATA et al. v. Monsanto. http://www.osgata.org/osgata-etal-v-monsanto/. Accessed 6 March 2014.

Schlager, E., \& Ostrom, E. (1992). Property-rights regimes and natural resources: A conceptual analysis. Land Economics, 68(3), 249-262.

The Genetically Modified Food (England) Regulations 2004 No. 2335. http://www.legislation.gov.uk/ uksi/2004/2335/introduction/made. Accessed 1 August 2014.

Thompson, P. B. (2007). Chapter 9: Conceptions of Property and the Biotechnology Debate. In Food Biotechnology in Ethical Perspective. (pp. 233-259). Springer.

UN. (2011). Nagoya-Kuala Lumpur Supplementary Protocol on Liability and Redress to the Cartagena Protocol on Biosafety. http://bch.cbd.int/protocol/NKL_text.shtml. Accessed 6 March 2014.

Van Asselt, M. B. A., \& Vos, E. (2008). Wrestling with uncertain risks: EU regulation of GMOs and the uncertainty paradox. Journal of Risk Research, 11(1-2), 281-300.

Van de Poel, I. (2011). The Relation between forward-looking and backward-looking responsibility. In Vincent, N., Van de Poel, I. \& Van den Hoven, J. (Eds.) Moral responsibility. Beyond free will and determinism. (pp 37-52). Dordrecht: Springer.

Van de Poel, I., \& Nihlén Fahlquist, J. (2013). Risk and Responsibility. In S. Roeser, R. Hillerbrand, P. Sandin, \& M. Peterson (Eds.) Essentials of risk theory. (pp. 107-143). Dordrecht: Springer. 107-143.

Van den Belt, H. (2009). Philosophy of biotechnology. In A. Meijers (Ed.), Philosophy of technology and engineering sciences handbook of the philosophy of science (pp. 1301-1340). Amsterdam: NorthHolland. 
Waldron, J. (2012). Property and Ownership. In Zalta, E.N. (Ed.) The Stanford Encyclopedia of Philosophy.

WTO. (2010). One Page Summary: EC-Approval and Marketing of Biotech Products. http://www.wto. org/english/tratop_e/dispu_e/cases_e/1pagesum_e/ds291sum_e.pdf. Accessed 23 Dec 2013. 